aid in throwing off the disease. The food of a human being may be full of the bacilli and still the system be so nourished that it will not retain the germs. While this may be true, still if the bacilli can not gain entrance into the organism there will be no danger of infection.

Tuberculosis is not so contagious as many diseases, but it holds its victims more firmly in its grasp than almost any other enemy of mankind. And yet this curse of the human race can be prevented. To accomplish this there must be strict sanitation. More and more attention is being given to the subject, not only by the physicians but by the people at large. To-day the hygiene of our cities is one of the great questions which municipalities have to deal. The sale of food that is infected with disease should be restricted and the punishment made so severe that the dealer will fear to sell such food. Each community should have an inspector, whose duty shall be to carefully examine all food sold. Some of our cities have greatly improved the quality of their milk supply by so doing. Sterilizing milk lessens the danger.

Milk containing tubercle bacilli is a diseased product. Wherever there is this microörganism there is tuberculosis. No tuberculous animal can give pure milk, the disease must affect all the organs of the body. Every cow, private or dairy, should be examined for tuberculosis and other diseases by an expert, and the milk of every new cow entering a herd tested before a drop of it is used. The inspection should be periodical, and carefully and systematically made. There should be a physical examination and the tuberculin test should be used, for it has been proved that milk from cows, which give no physical signs, is often infectious. Although Koch's tuberculin has not been a success as a thereapeutic agent, it has proved a useful aid in the diagnosis of tubereulosis, and no herd can be thoroughly inspected without its use. The healthy cows should be marked, and all tuberculous animals. no matter how slightly affected, destroyed. It is a serious matter to go into a man's herd and kill his cattle, but it is pernicious to let such animals live, a menace to a community.

Not only should the cow be inspected but its treatment and surroundings. The animal from which milk is taken should have the best of care, be fed wholesome food and have stables and surroundings neat and comfortable. The utensils used for holding milk, making butter and cheese should be clean and free from dust. No person suffering with tuberculosis should be employed about a dairy, creamery or where food is prepared or sold.

Only milk and its products from inspected dairies should be placed on the market. There should be abattoirs where the slaughtered animals could be examined by competent experts, and no market should be allowed to sell meat which does not have the inspector's tag.

All articles of diet should be kept from contaminating dust. Even the wrapping paper may infect healthy food. Eating utensils used by consumptives should be disinfected.

Inspection is a necessity. To make it a success the inspectors should be educated men and their decisions enforced by law.

The cost of sickness is great, so immense that we fail to grasp its magnitude, nor can we form a proper conception of the annual financial loss to the nation from this king of terrors. Every life has a financial value, every life saved is so much gained for the community. The child who dies before he is able to be a wage earner, is a loss of just so much as has been expended on him and what he could have earned had he lived. When a man dies of this disease it is not alone the expense of his sickness and the value of his wages that are lost to the world, but the time of those who cared for him, and the expense of the expanding influence of the disease he has left behind bim.

With the worderful development of our country comes increasing danger of infection from the foreign element which, absorbed by our people, by its lack of ordinary sanitary precautions aid in spreading disease. There is a demand for better means of protection.

Every charitable institution in this land is an unconscious recognition by the people of the importance of sanitation and teaches that man should not live for himself alone, but for humanity. It is our duty as physicians to devise means for the amelioration of the human race.

Progress in preventive medicine has given us facts that prove the danger and has shown us a logical means of prevention. With this light to aid us we must impress the truths upon our fellow men.

The people are thinking about these things and are increasing in knowledge; public opinion in all its unmeasured power is slowly progressing.

Education and a wise use of education will do much, but an educated people can not do all. There must be a willing government to enforce. The growth of sanitary science calls for advancement in controlling sanitation. State and local authorities can not shirk the responsibility; they are bound to protect life from the danger of death by disease, as from rapine and murder, no matter how great the expense. For a municipality to pay no attention to the sanitary condition of the community is to become the abetter of crime. Some of the States have taken up the subject and their health officers have done noble work in checking the advance of disease, but in order to do the greatest good to the greatest number there must be more legislation in favor of sanitation. There must be intelligent men at the outposts, guarding hamlet and city, a united action along the line, with a master mind at Washington advising and control. ling the entire force.

When advancing civilization shall recognize justice to humanity and give place among our Presidential advisers to a man of science who will guard the common safety and welfare of our nation, lessening sickness and want, sorrow and suffering, wasting and death, then may we hope to see science triumph over disease.

\section{MODERN RESPIRATORY ADVANTAGES.}

Read in the Section on State Medicine, at the Forty-seventh Annual Meeting of the American Medical Association, held at Atlanta, Qu., May 5-8, 1896 .

BY W. T. ENGLISH, A.M., M.D.

PROFESSOR OF PHYSICAL DIAGNOSIS IN MEDICAL DEPARTMENT OF WESTERN UNIVERSITY OF PENNSYLVANIA, AND CONSULTANT IN CHEST DISEASES IN TIIE SOUTH SIDF HOSPITAL. PIT'TSBURG, PA.

The worker in the domain of preventive medicine often has occasion to feel that there are excuses for becoming pessimistic and for regarding his efforts as unprofitable. After some acute outbreak of disease, his heart is wrung with disappointment and his mind is distracted. A good remedy for such hypochondri- 
asis is to rehearse for himself, or have another review for him, some of the modern respiratory advantages, and trace them to their source. All men are not alike possessed of the "vision and faculty divine," but that man must be indeed prosaic whose soul is not inspired with gratitude and whose heart is not uplifted with hopefulness as he beholds the human body rapidly and surely raised from the abnormalities of life, sublimated, refined and sacred through the avails of modern respiratory advantages. The individual who labors in the realm of preventive medicine is habituated to a life amid the vapors of melancholy and disease, and if no sudden or colossal change dispels those vapors, his mental visualizing is rarely illuminated. However, his efforts are continuously transforming the gruesome abiding places of disease into palaces of good cheer, and he is creating an improved state of existence for himself and his generation. The influence ceases not, but it steeps in splendor the distant human prospect and reaches out its long arms like a benediction toward the ages that are yet to be.

The solicitude with which he guards the youth from the moment he leaves the nursery is like to the fabled spirit of good that keeps from all evil. So unremittingly has he demonstrated the ill influences of bad air and advonated the benefits of good respiration that the school curriculum has been extended to include a study of the laws which govern the respiratory organs, with those which govern other material things. By the intelligent application of the laws of respiration, which the schoolboy is thus taught to understand, there is not only a continuous development of the breathing apparatus, but an extension and versatility of its functions. The schoolboy of to-day knows better how to breathe than does his grandsire. In him is awakened an appreciation of the fact that the respiratory organs were never intended to act as involuntary parts of the body, and it becomes a portion of his daily care to observe that a fair proportion of the 25,000 respiratory cycles are voluntary and forcible acts. This age, so self-conscious in many things, is thus to be secured against lethargic, indifferent and unconscious respiration, which has been the cause of much of the pulmonary weakness of the past. . The most casual observer will note that it is not our boys and girls who need reformation from respiratory delinquencies, but the fathers and mothers. It is only the children who have learned from their teachers how to use their respiratory organs who really know how to breathe. The large majority of those in adult life have never yet learned how to take a full inspiration or execute a forced expiration. They are totally ignorant of what is meant by a voluntary respiration. In consequence of this the average adult never employs the lungs beyond that which is essential to existence, and to those engaged in sedentary pursuits this need is exceedingly small. On the other hand, every child, disciplined to-day in the accepted respiratory school, is capable of taking in twice as many cubic inches of air as his parent, and habitually uses his breathing organs with proportionately greater freedom and scope. In comparison with the school children of to-day the parents are a race of pulmonary pigmies.

This constant oversight of the lungs brings with it respiratory fulness with perfect oxygenation that in turn develops material out of which energy proceeds. The augmented lungs and extended respiratory action begets an increased desire for air, and these promote a condition of mind that is emulous of bright surroundings. There is nothing that secures appreciation of hygienic conditions like a personal experience of their benefits. To one thus endowed there is a delicious sense of pleasure in the pressure of the lungs against their confines, and it is not easy to deprive him of his powers to battle with bad air.

These methods of cultivation secure an esthetic and cultured respiratory demeanor and at the same time create a longing for complete and repeated changes of air, much as the cultivated taste of the epicure delights in changes of viands. How young, wholesome lungs do yearn for some new brand of alveolatitillating atmosphere! Moreover the highly educated breathing apparatus has analytical capabilities so that it may appreciate that a molecule of oxygen is an impact of two atoms of the element while it recognizes a molecule of ozone as a combination of three. Furthermore, the lungs feel the corroding energy of the triplet to be many times greater than that of the twin, and the influence it exerts upon the breathing apparatus exemplifies a higher intelligence than mere automatism. An educated pair of lungs observes that the air is not imponderable and notes the thermometric and the barometric rise and fall. The mind and the lungs together grow familiar with the physical character of the air, its invisible inhabitants, the microbes and their potencies for good or ill, as well as the general and specific qualities of the air dust.

If it is true, as is calculated, that in the air of the city a man breathes $37,000,000$ spores every ten hours it is not from aerial purity that any of the city denizens continue to live and move and have their being. It is also well known that in the atmosphere everywhere there is an opulence of oxygen and the greatest need is a capacious and intelligently controlled breathing apparatus to utilize it, and at the same time to successfully conduct the hygienic chemistry of the perfect function. The educated and sensitive lungs will isolate the deleterious ingredients more rapidly than the microscopist or the chemist; and those objects entrapped upon the microscopic slide, which appear so interesting and beautiful to the visual sense are altogether unlovable to the breathing apparatus when they gain access within their sacred precincts. This ever-increasing discriminating capacity of the human lungs enables men to remain for a season amid deleterious influences with comparative safety.

It was assumed many years ago that the coefficient of oxygen needful and belonging to animals was fixed by the animal's intelligence. Thus, a dog required more oxygen than did a hare of equal weight; the chimpanzee, the nearest animal to man in point of anatomic resemblance, needed less than man. Whether these estimates were considered fanciful or not, it is certain that to breathe well to-day is the most modern method of demonstrating advancing intelligence.

Falling in line with this display of wisdom in the exercise and development of the lungs are the efforts that are everywhere made to reduce the aerial threatenings and improve the quality of the air we breathe. But for these efforts the vitiated city atmosphere would be most deplorable in its consequences to those compelled to remain within the urban limits. However, it is only amid such surroundings that we can discover how apparently insensible some persons are to the subtle influence of vicious atmosphere, and 
observe the variety of means which contribute to counteract the bad air and unhygienic conditions.

The elaborate and perfect system of interchange that has been going on since the world began between the earth, the vegetable and the animal kingdom, with no waste of material, still continues to command the admiration and thanks of every grateful creature. This is also supplemented by a process of sanitary chemistry-more flexible and variable-by which the actions and reactions of materials and the affinities and aversions of the silent and unseen forces are made to conform in the main to the best interests of human kind through the provisions of the vis medicatrix naturee.

To reinforce these natural efforts at sanitation, every city to-day has in its employ a capable corps of workers whose business it is to look after the various impurities. It is the custom in several municipalities to gather a measure of the atmosphere from different portions of the city and force it through materials in which are entrapped the impurities, and these are carefully isolated and estimated, and the result announced. To afford all who desire to acquaint themselves with the relative impurities existing in different localities a record is made at intervals not exceeding one week.

The use of the microscope and other instruments of investigation has become popular amusement, and there is an individual as well as public surveillance of the atmosphere. Through thousands of channels of observation the intelligent layman is accumulating experience that enables him to trace facts and inferences to their logical conclusions, and the good results are constantly multiplying. Knowing that evils exist he seeks to prevent their influences in himself and others, and though his supremest need demands his presence for a season amid the unwholesomeness, he provides himself with a home beyond its contaminations, where he can retire after his daily duties are over, and render his lungs clean again ere he starts them upon their fresh career of defilement. His household is continuously kept amid the respiratory advantages.

Toward the attainment of these possibilities every recent invention seems to felicitously trend. The proper thing is ever more and more becoming the popular thing. In modern street paving there are some remarkable advantages secured to the respiratory apparatus. The myriad crevices favoring the accumulation of dust and offal in the cobble-stone pavements are replaced by the smoother surfaces of the granite and asphalt. These pavements in the streets of the present city make the dust obvious to the street cleaner, and spontaneous removal by rainfalls is facilitated. The frequent use of the sprinkling cart has a salutary effect in lessening the contamination of the respirable air. We have recently bade adieu to the lumbering horse cars and the thousands of horses which contributed to the filth of every city. The dust, the offal, exhalations, effluvia, gas and odors innumerable incident upon the vast herd of horses upon the streets are no longer with us. By the electric and cable cars thousands of horses in addition to those formerly employed by the horsecar companies are rendered unnecessary. The commodious and wholesome rapid-transit cars are a desirable means of conveyance and the great celerity of travel yields additional advantages by expediting business, social and pleasure trips. By the reduction of evil long prevalent, and the substitution of the most royal good, they contribute to modern respiratory advantages beyond computation.

The more recent methods of city illumination has done much that is favorable to wholesome activity in the breathing apparatus. The old-time fishtail gas jet, capable of consuming as much oxygen as several persons, is substituted by the electric light. This is especially noticeable in assembly rooms. By the use of electric light there is no oxygen waste and no products of imperfect combustion. Its universal employment would cause an oxygen saving to every city sufficient to supply twice the number of its inhab. itants with good wholesome air.

In the matter of heating, the respiratory organs are considered. The air is not permitted to become gloomy with smoke and other evidences of imperfect combustion, and the smoke-consumer is voluntarily or legally adopted. In the homes we can have our apartments warmed by the moist or dry methods and can so arrange that there will be an equable continuous dry atmosphere, free from dust. Again, we may imitate the barometric rise and fall to suit our fancy or gratify our wish. In the districts where natural gas abounds the air can be kept free from smoke by its employment as a fuel and without even the annoyance of dust from ashes. Some of the more recent methods of supplying air and heat to modern buildings embrace advantages that are destined to lift us out of the empire of death from aerial impurity. The air is drawn by fans through closely woven silk screens or forced through baths which wash and ren-. der it aseptic. The shafts into which the atmosphere is drawn are extended to a high altitude to avoid the dust and contamination. After gaining admittance to the basement it receives the desired barometric and thermometric qualities before it is delivered through. out the building. In each room is placed an indicator with a movable needle by the least motion of which the temperature of the apartment can be changed. This adjustment resembles that portion of our timepieces which enables us to regulate its speed. Hundreds of other aids and means of protection to the developing breathing apparatus can be observed in modern city building.

How eminently fitting that an age which protects and fosters its respiratory good should form a remarkably close alliance between its pastime and its business. Wherever we go on a Saturday afternoon we find the city denizens hastening, by every avenue, from the crowd and tumult into the more rural surroundings. The old dead roadways, that a few years ago were overgrown with weeds and grasses, teem with cyclers, and the little town along the way lifts up its head again as if possessed of a new life. The glorious half-holiday rescues many a failing respiration from the thraldom of disease. To take a stroll or join in some of these methods of oxygen hunting, or spend the Sabbath amid nature's wholesomeness, is to serve God. A half century ago this would have seemed sacrilege and the Saturday half holidays would have been regarded by our grandsires as sinful and profligate. But this is the end of the nineteenth century and the world is growing young again through its modern respiratory advantages.

Cricket, football, baseball, tennis, golf, fishing and athletics generally are familiar to every place and are regarded as suitable pastimes for all young Americans. How they have aided in the resuscitation of some of 
the yielding respiratory organs! It is not the schoolboy, neither the idle men of means who are interesting themselves in these sports and pastimes, but the masses. The countless excursions by rail or water are daily inviting a willing humanity to bathe their bodies in the sunlight and purify their lungs in the aerial change. Whatever morsel of air or quality of atmosphere one desires may be secured by application to the numerous competing land or waterways, and he will comfortably, cheaply and with great celerity be transported to the Eldorado of his desire. With these new experiences and ever-changing quality of the respired air the lungs not only develop their vital capacity but acquire a versatility in their methods of accommodating themselves to the aerial circumstances. There is undoubtedly a remarkable adaptability by which the lungs may adjust themselves to the conditions. And this serves their possessor in good stead when it is impossible to select the environments, because the respiratory versatility enables him to breathe the disease-ladened air with comparative impunity. Man is to-day capable, for the most part, of educating and subjugating nature, and when the surroundings are at fault he makes or modifies them; failing in this, he can rely upon the discriminating care acquired by his lungs to render the atmospheric foes inert.

Through all the avenues of hygienic information the truth is being ever more and more impressed that pure air and exercise are equal forces acting in the same direction. The contaminations from disease germs and terrestial impurities are to be met by an equable antagonism vouchsafed through the intelligent employment of the functions of respiration. Meanwhile most of us agree with Lord Beaconsfield that "the atmosphere has more to do with human happiness than all the accidents of fortune and all the acts of government."

The adjustment of the respiratory possibilities to the needs of each individual is largely a matter of his own choosing. There are some who have tarried too long under the lethal influences of indifferent respiration, and have in consequence bartered their birthright. Some again there are whose lungs, like the Scotch farms of which we read, are "poor by nature and ruined by cultivation." There may be no regal duty for such to perform but even these can hold from future human struggle the burden of preventable suffering by negatively remaining away from the current of human life that is to-day flowing so directly toward the goal of physical completeness.

$$
\text { DISCUSSION. }
$$

Dr. Kellog - In a certain school there was considerable difficulty in persuading the Indians to attend. I thought they would be glad to avail themselves of the opportunity. They were still in a primitive state and were running about in the forest absolutely nude. There was a lot of Indians who thought it unhealthy to be in the house, and took their children away on that account. It was instructive to me to see that they were so solicitous about their children's health.

He said we did not know how to breathe unless we learned it at school. It is not even known in school. I found the best teacher for breathing was a baby. The good Lord told them how to breathe and they breathe just right. I have told many ladies that the best of their breathing powers were tied up; and that if they wanted to learn how to breathe to take a baby and lay it on a bed, and notice how it breathes. I say breathe with the whole trunk. When he breathes the whole trunk will be inflated.
Women breathe with the upper and men with the lower part of the body. What all need is full respiration of the entire chest. I have two little boys and I frequently make them run up and down stairs once or twice to make them breathe properly.

I formerly practiced voluntary respiration, but I am convinced it is not a success. Simply breathing or exercising for the sake of it is tiresome. I have not been able to breathe voluntarily more than two or three minutes at a time. The muscles very soon get tired. But if you will compel yourself to breathe by bicycle riding, jumping up and down, room exercising, or anything else that will create a demand for pure air you will find that it is not so tiresome. The lungs will act in the most vigorous and voluntary manner. For the last seven years I have used gymnasiums for my patients with excellent results.

Dr. - , in some experiments made in the Dangerfield Academy, showed that after six months exercise in the gymnasium he found that the involuntary activity of the lungs was doubled. It became twice as great while the students slept, showing that the effects of gymnasium work are continuous during sleeping as well as waking hours.

There is another point: The position assumed in sitting. A lady said, "I want to talk to you about my lungs. My mother thinks I am to have consumption because I have no chest." I made her stand up and she stood with shoulders and chest contracted. A ruler laid on the chest would have touched the shoulders on either side. I made her bend and look upward, and found she had a well developed chest, but was carrying it all behind instead of in front. The lungs had not been properly expanded. In making her stand straight I entirely corrected the deformity. It is becoming a very common deformity. I think it is largely caused by sitting on the back instead of on the thighs, and it results in people becoming round-shouldered. The body is held in this mold for so long a time that it finally acquires a certain degree of permanency.

The doctors ought to be continuously calling attention to standing straight and raising the chest. While standing straight the lungs are expanded, and the abdominal viscera trained up. Walking, boxing, bicycling are agreeable and exhilarating, and accomplish these beneficial results. They render proper breathing more natural.

Dr. GARBER - I have had considerable practice with men who were engaged in blowing window glass, and it has been my experience, that forced exercise will cause great development of the chest. In 500 glass blowers I can not remember a single case of lung trouble. I used a respirometer on some of these men, and found they can inhale 300 cubic inches of air, and I frequently found a difference of five and sometimes six inches between inspiration and expiration. Some people whom I regarded as consumptives have since become well, and lungs predisposed to disease of that kind became strong. I am very much in favor of gymnasium exercise of some kind for all.

Dr. KeLlogG-The atmosphere is as important to us as the water that we drink, or the light that shines upon us. I want to ask a question in regard to the consumption of this oxygen; I want to ask the author if he thinks that it would materially affect the health of the city to change to electric lights on account of more consumption of oxygen by gas jets than by the electric lights.

Dr. ENGLISH-I made, some time ago, an investigation as to the consumption of oxygen by the ordinary gaslight jet, and it showed that one gas jet consumed as much oxygen as would supply three ordinary persons. Assuming, then, that we have 100 lights in the assembly room, and 300 persons. We would have consumed by the lights as much oxygen as would have been consumed by the individuals in that room.

When we build a room the area is usually estimated to accommodate a certain number of people, and a building of 
wholesale emporiums is usually conducted upon the principle that so many cubic inches of air must be supplied to every individual. When we use the electric light, especially the incandescent, we consume no oxygen. The incandescence of the carbon must be considered the source of light. It burns in a vacuum, with no possible oxygen waste. In every city we have a certain proportion of people living in one room. Estimate the number of rooms in the city, and in that way we can estimate approximately the amount of oxygen we are consuming by the use of these burners. Then there is another point; just estimate the amount of contaminations, the smoke, gas, odors, and the various emanations which are contributed to the oxygen by these fish-tail gas jets, and the heat that the gas produces, whereas, with electric incandescent lights burning in a vacuum, we have a brilliant light that is satisfactory, comfortable to the eyes, do not have these contaminations, and we have a minimum amount of heat. The consequence is that we do not vitiate the atmosphere. With are burners on the streets and in the rooms we would have a much larger result, for one arc burner was estimated to be equivalent to sixteen times the power of the ordinary burner, I believe. The comparison is between the two different kinds of light. The arc burner is exposed to the atmosphere, and consumes a large quantity of oxygen; but there is no comparison that would demonstrate the advantage that would be accorded the electric light. When we go back to oil lamps and candles and such devices for lighting purposes, they are often worse, because their contributions to the atmosphere are vastly in excess.

It is a fact that we do not in the schools to-day teach the children how to breathe. We should impress upon them that there are vital organs in the human body and that it is within the capacity of our volition to control these organs, these lungs. We may breathe fast or slow as we choose, and take in as much or as little air. We may suspend respiration, but we can not suspend the action of the mind enough to prevent the use of our lungs. I think Nature has demonstrated by placing these organs within our body it is our duty to use them, or they are indeed not vital organs. By that means Nature secures for us perfect respiration, good sound lungs and a wholesome body.

Dr. KelLoGG-I just want to mention three disadvantages: gas stoves, kerosene stoves and gas grates as heaters. A doctor put a kerosene stove in a room and the next day the patient was dead. He told me he was satisfied the patient was suffocated by the odors arising from the stove. The gas stove produces ten times as much impurity as an ordinary gas burner, and a gas grate gives out at least twenty times as much impurity as a gas burner. It seems to me a very dangerous thing.

Dr. FNGLISH-I would like to ask the gentleman what gas he has reference to-artificial, natural, illuminating or what?

Dr. KELLOGG-It is coal gas. That is a hurtful gas. In natural gas heaters as well as in grates, the opening for the escape of the gases is in some scarcely 1,8 of an inch in width, so when the door was opened it was certain to drive all the foul gases out into the room, so that I think it applies to both natural and artificial gas.

- The Chairman - I think the general fashion of ladies' dresses is wrong, and that the weight instead of hanging from the hips, as is now the case, should hang from the shoulders. I think until that is done they will never have perfect respiration, and that if Dr. English will start a crusade on this line it will result in much better health in every respect, and especially there will be less falling of membranes which the women complain of so much and which gives the gynecologists so much work. They should also have their dresses made so that two or three inches additional would be allowed for expansion of the chest.

DR. ENGLish--I think that the efforts of such reformers as
Jenness-Miller have influenced the women, and in my experience--and I have had rather large experience in respiratory difficulties because my special realm is the treatment of diseases of the chest--I find that women are disposed to lay aside their pains and corsets and take up more life and health. I really think if I incorporated that subject in my paper I should have illustrated the women of the future. They are growing sensible as well as the men.

Dr. DRaYTon--This Jenness-Miller reform is simply a departure from the strict lines of fashion. It is simply an attempt to adapt certain principles of hygiene to fashionable dress. You may get some benefit from it, but it appears to me that the attempt will not be more beneficial than the attempts already made on that line. The new woman will make some difference in this matter of fashionable costume. The new woman ilkes the bicycle and the woman who rides finds it necessary to adopt a bicycle costume. She finds it is not only good to make muscle in the arms but also in the abdominal region, and after a little practice she would prefer to put her finger in the face of fashion than to give up the wheel. So I think we shall have a great improvement from this cause. I have advised the use of the wheel to a great many ladies. I have studied it and its advantages and I am satisfied its general use will be of great benefit.

Dr. J. A. Work, Indiana-The wheel is not available to all. We should give our women more employment that will have the effect of developing what is claimed for the wheel, which is for amusement, but as a vocation I believe general housework, such as our mothers and grandmothers used to do, would be better for them. I have found that the German servant girls who have not followed fashion have very good breathing apparatus and very good lungs. They stand erect and they have employment that compels them to do it. They have to breathe right and they have to clothe themselves right or not do the work required of them. Two young Swedish ladies came to my office for treatment. One wanted to know what was the matter with her side. I put my hand on the side of the chest and told her to take a long breath and her chest shoved up under her chin. She could not expand it around the base of the lunga one-half inch. Under the armpits above the breast she expanded three inches. I said: "That is the trouble with your side ; take off your corset and you will breathe well." Let us give them employment that will make them breathe.

Dr. H. E. Garrison, Illinois--I believe I am the only woman doctor present. I have practiced for twenty years and I can ride and walk as readily with as without a corset. Mrs. J. S. Lane has a book upon the subject and if the gentlemen will read it they will know why we have worn corsets and will continue to wear them as long as we live.

\section{SURGERY OF THE KIDNEY.}

BEING A STLDY OF A SERIES OF CASES IN WHICH METHODS OF DIATNOSIS AND TREATMENT ARE ILIUUSTRATED.

\section{BY BAYARD HOLMES, B.S., M.D.}

PROFESSOR OF PRINCIPLES OF SURGERY IN THE COLLEGE OF PHYSICIANS AND SURGEONS OF CHICAGO.

TCBERCULOSIS OF THE KIDNEY.

In this series of cases two appear to have been tubercular, although in neither case was an absolute diagnosis made before operation, and in the second case doubt still remains as to the real cause of the disease. In both cases, however, all the means of diagnosis known, except inoculation experiments, were made, and every step was guided by positive indications for treatment. In the first case, Mrs. S., nephrectomy was contraindicated by the desperate condition of the other kidney, determined by catheterizing the ureters. In the second case, Miss C., unusual 